\title{
Le choix d'écrire en français. Études sur la francophonie translingue, C. Allard et S. De Balsi (dir.)
}

\section{Emanuela Cacchioli}

\section{(2) OpenEdition}

1 Journals

\section{Edizione digitale}

URL: http://journals.openedition.org/studifrancesi/10611

DOI: 10.4000/studifrancesi. 10611

ISSN: 2421-5856

\section{Editore}

Rosenberg \& Sellier

\section{Edizione cartacea}

Data di pubblicazione: 1 décembre 2017

Paginazione: 591

ISSN: 0039-2944

\section{Notizia bibliografica digitale}

Emanuela Cacchioli, «Le choix d'écrire en français. Études sur la francophonie translingue, C. Allard et S. De Balsi (dir.)», Studi Francesi [Online], 183 (LXI | III) | 2017, online dal 01 février 2018, consultato il 21 janvier 2021. URL: http://journals.openedition.org/studifrancesi/10611 ; DOI: https://doi.org/10.4000/ studifrancesi.10611

Questo documento è stato generato automaticamente il 21 janvier 2021.

\section{(c) (1)}

Studi Francesi è distribuita con Licenza Creative Commons Attribuzione - Non commerciale - Non opere derivate 4.0 Internazionale. 


\title{
Le choix d'écrire en français. Études sur la francophonie translingue, C. Allard et S. De Balsi (dir.)
}

\author{
Emanuela Cacchioli
}

\section{NOTIZIA}

Le choix d'écrire en français. Études sur la francophonie translingue, sous la direction de Cécilia ALLARD et Sara DE BALSI, Amiens, Encrage Université, 2016, 121 pp.

Il volumetto, che si propone di raccogliere gli atti della giornata di studi organizzata dai giovani ricercatori del Crtf il 15 ottobre 2014, affronta la francofonia da una prospettiva particolare. L'opera è, infatti, dedicata agli autori che utilizzano il francese come lingua letteraria pur non essendo nati all'interno di una comunità francofona. Dal punto di vista quantitativo, si annovera un numero esiguo di scrittori e diviene difficile operare una classificazione e darne una definizione. Numerosi tentativi sono già stati fatti in questo senso a partire dagli anni Novanta e, nell'introduzione, le curatrici del volume effettuano un excursus storico per rintracciare l'evoluzione di tale approccio. Cécilia Allard e Sara De Balsi identificano il volume Poétiques francophones di Dominique Combe come prima tappa di questa carrellata. Il critico sostiene che occorre parlare di francofonia individuale e non considerare solo la dimensione collettiva (vi sono autori che scrivono parte della loro produzione letteraria in francese pur avendo imparato l'idioma in età avanzata). Da questa prima menzione si apre il dibattito sulla questione e molti critici offrono il loro contributo. Robert Jouanny utilizza l'espressione «diaspora optionnelle» (p.9) per rintracciare le motivazioni alla base della scelta della lingua: storiche, familiari, politiche, morali, psicologiche, culturali o fortuite. Anne-Rosine Delbart privilegia l'aggettivo «francese» per indicare l'idioma utilizzato e definisce questi autori come degli «exilés du langage» (p.10). Véronique Porra seleziona il suo corpus a partire dalla volontà dei romanzieri: scelgono di scrivere nella «langue d'adoption» durante la giovinezza o l'età adulta. Ursula Mathis-Moser e Birgit Mertz- 
Baumgartner sono ricorse invece alla definizione di «écriture migrante» (p.11) per indicare anche quegli scrittori che hanno vissuto l'emigrazione in modo consapevole e che pubblicano con editori francesi. Chiude la carrellata Alain Ausoni che utilizza l'aggettivo «translingue» (p.12) per definire la pratica della letteratura solo in lingua seconda. L'aspetto originale di questo approccio, considerato come filo conduttore anche del presente volume, è l'elaborazione dell'immaginario linguistico che si ripercuote inevitabilmente nelle creazioni letterarie. Gli autori analizzati dai vari critici sono sicuramente accomunati dal cambio di idioma e dalla sensibilità alle problematiche linguistiche. In altre parole, la scelta del francese implica una riflessione da parte degli scrittori stessi che emerge in qualche modo nei loro testi.

2 Al termine dell'introduzione in cui viene effettuata una panoramica della situazione e delle prospettive critiche già sviluppate, il volume si presenta come una raccolta di saggi che ruota attorno a vari interrogativi: l'approccio nei confronti della lingua adottata (necessità di una rivendicazione, di addurre una giustificazione), la rappresentazione dell'idioma nelle opere, l'immaginario che ne viene evocato, il rapporto che intercorre tra gli autori e le istituzioni francofone, oppure, al contrario, come queste ultime considerano gli scrittori «translingui». La raccolta di articoli si apre con il contributo dello stesso Alain AUSONI, La langue qui s'impose (pp. 21-30) che riflette sulle motivazioni che possono condurre alla scelta di adottare il francese come lingua di scrittura. Individua tre tendenze: alcuni autori avvertono un'attrazione irresistibile per il francese; altri lo utilizzano per distanziarsi dalla propria lingua materna e ricorrono a una mediazione; il terzo gruppo comprende gli scrittori che devono confrontarsi necessariamente e quotidianamente con il francese. Dello stesso tenore è l'articolo di Sara DE BALSI, Hypothèses sur le "discours translingue": paratopie, positionnement, postures (pp. 31-42), la quale si sofferma sull'atteggiamento che gli scrittori manifestano nelle loro produzioni letterarie.

3 Segue una sezione dedicata a visioni collettive. Zheng DONG, con Le contexte historique de l'émergence des écrivains chinois francophones (pp. 45-54), offre una carrellata degli scrittori cinesi che hanno avuto successo con la lingua francese nell'ultimo secolo. Cécilia ALLARD, Les écrivains espagnols et la langue française: un choix en partage (pp. 55-65) si focalizza sugli autori spagnoli che hanno adottato il francese dopo aver subito la guerra civile che li ha costretti all'esilio. La scelta di un mutamento linguistico che non va di pari passo con lo stile è, invece, la strategia intrapresa dagli scrittori ebrei del Mediterraneo, di cui rende conto Elisabeth ScHuLz in Les invités de la langue française: la francophonie des Juifs méditerranéens (pp. 67-81).

4 Chiudono la collettanea tre contributi che si soffermano su percorsi individuali dove spesso troviamo la compresenza di più lingue: La nouvelle langue de Georges-Arthur Goldschmidt, une expérience de l'extraterritorialité (pp. 85-92) di Thibaut CHAIX-BRYAN, La violence de la dite "assimilation": le cas d'Hector Bianciotti (pp. 93-100) di Luciano BRITO e Du choix d'écrire en français au refus de la francophonie: le cas d'Anna Moï (pp. 101-116) di Julie ASSIER.

5 Il volume offre alcuni spunti di riflessione su un tema ancora poco studiato. Gli autori che utilizzano il francese come lingua di scrittura pur non essendo l'idioma materno non sono moltissimi e, soprattutto, resistono alle classificazioni e alle etichette, dal momento che ciascuno di loro parte da motivazioni diverse. Eppure si tratta di un interessante filone che meriterebbe maggiore attenzione. Ben vengano dunque 
convegni e singoli approfondimenti come questo che possono arricchire ulteriormente questo filone di studi. 